\title{
Does methotrexate influence COVID-19 infection? Case series and mechanistic data
}

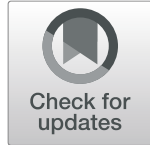

Fabian Schälter ${ }^{1,2}$, Kerstin Dürholz ${ }^{1,2}$, Laura Bucci ${ }^{1,2}$, Gerd Burmester $^{3}$, Roberto Caporalii ${ }^{4}$, Camille Figuereido ${ }^{5,6}$, Jaime Fogagnolo Cobra ${ }^{5,6}$, Bernhard Manger ${ }^{1,2}$, Mario M. Zaiss ${ }^{1,2}$ and Georg Schett ${ }^{1,2^{*}}$

\begin{abstract}
Background: To investigate whether methotrexate treatment may affect the susceptibility to infection with severe acute respiratory syndrome coronavirus 2 (SARS-CoV-2).

Methods: Clinical assessment of symptoms, SARS-CoV-2 RNA, and anti-SARS-CoV-2 IgG in an initial case series of four families and confirmatory case series of seven families, within which one family member developed coronavirus disease 19 (COVID-19) and exposed another family member receiving methotrexate treatment; experimental part with methotrexate treatment of mice and organoids followed by the assessment of mRNA and protein expression of the SARS-CoV-2 receptor angiotensin-converting enzyme (ACE)-2.

Results: In the initial case series, three of four women on a joint ski trip developed COVID-19, while the fourth woman, under treatment with methotrexate, remained virus-free. Two of the three diseased women infected their husbands, while the third husband treated with methotrexate remained virus-free. In addition, 7 other families were identified in a follow-up case series, in which one member developed COVID-19, while the other, receiving methotrexate, remained healthy. Experimentally, when mice were treated with methotrexate, ACE2 expression significantly decreased in the lung, in the intestinal epithelium, and in intestinal organoids.
\end{abstract}

Conclusion: These clinical and experimental data indicate that methotrexate has certain protective effects on SARSCoV-2 infection via downregulating ACE2.

Keywords: Methotrexate, Coronavirus disease 19, Infection

\section{Background}

Severe acute respiratory syndrome coronavirus 2 (SARS$\mathrm{CoV}-2)$ enters epithelial and other cells through binding to angiotensin-converting enzyme 2 (ACE2) expressed on various epithelial cells including those of the lungs and the gut [1]. SARS-CoV-2 entry into human cells triggers cell damage associated with a robust and sometimes overshooting inflammatory responses in the

\footnotetext{
* Correspondence: georg.schett@uk-erlangen.de

${ }^{1}$ Department of Internal Medicine 3, Friedrich-Alexander University (FAU) Erlangen-Nürnberg and Universitätsklinikum Erlangen, Erlangen, Germany ${ }^{2}$ Deutsches Zentrum fuer Immuntherapie (DZI), Friedrich-Alexander University (FAU) Erlangen-Nürnberg and Universitätsklinikum Erlangen, Erlangen, Germany

Full list of author information is available at the end of the article
}

affected organs and the development of coronavirus disease 19 (COVID-19 [2].

The level of ACE expression by lung epithelia may influence the susceptibility to SARS-CoV-2 infection. For instance, low ACE2 expression in young mammals can potentially explain the overall low susceptibility of children to COVID-19 and other zoonotic coronaviruses [3]. Furthermore, smoking as well as high salt diet have shown to increase ACE2 expression, which may explain the higher risk for COVID-19 in smokers and those with hypertension, respectively $[4,5]$. In addition, administration of recombinant soluble ACE2 saturates cellular surface ACE2 outcompetes viral binding sites and hence is

(c) The Author(s). 2021 Open Access This article is licensed under a Creative Commons Attribution 4.0 International License, which permits use, sharing, adaptation, distribution and reproduction in any medium or format, as long as you give appropriate credit to the original author(s) and the source, provide a link to the Creative Commons licence, and indicate if changes were made. The images or other third party material in this article are included in the article's Creative Commons licence, unless indicated otherwise in a credit line to the material. If material is not included in the article's Creative Commons licence and your intended use is not permitted by statutory regulation or exceeds the permitted use, you will need to obtain permission directly from the copyright holder. To view a copy of this licence, visit http://creativecommons.org/licenses/by/4.0/ The Creative Commons Public Domain Dedication waiver (http://creativecommons.org/publicdomain/zero/1.0/) applies to the data made available in this article, unless otherwise stated in a credit line to the data. 
effective in preventing SARS-CoV-2 infection of human tissue organoids [6].

To date, little is known on whether anti-inflammatory drugs used for the treatment of immune-mediated chronic inflammatory diseases (IMIDs), including arthritis, could influence ACE2 expression and affect susceptibility to SARS-CoV-2 infection. Herein, we report on case series of families, in which one family member developed COVID-19, while the other family member, taking methotrexate (MTX), remained virus-free and healthy despite substantial viral exposure.

\section{Methods}

\section{Ethical approval}

Ethical approval (\#157_20 B) to conduct this analysis was granted by the institutional review board (IRB) of the University Clinic of Erlangen. Written informed consent was obtained from the study participants.

\section{Participants}

Data were obtained from [1] an initial patient group of 4 women performing a ski holiday at Ischgl (Austria) and their respective husbands and 7 confirmatory cases from Italy [2], Brazil [4] and Germany [1] comprising families with one member infected with COVID-19 and the other member taking methotrexate staying healthy. In the initial patient group, methotrexate was used for treatment of psoriasis [1] and rheumatoid arthritis [1]. In the confirmatory cases, methotrexate was used for treatment of rheumatoid arthritis [4] and psoriatic arthritis/spondyloarthritis [3]. Doses of methotrexate were between 10 and $20 \mathrm{mg} /$ week.

\section{Symptoms}

Participants were asked for their clinical symptoms (cough, rhinitis, throat pain, fever, headache, fatigue, musculoskeletal pain, anosmia, shortness of breath, and diarrhea) according to a questionnaire that was used for a field study on anti-SARS-CoV-2 IgG [7]. The observation period in the initial and confirmatory cases was 1 month.

\section{SARS-CoV-2 RNA test}

RNA quantification was down from mucosal swabs using Cobas SARS-CoV-2 real-time RT-PCR Test (Roche, Basel, $\mathrm{CH}$ ).

\section{Anti-SARS-CoV-2 antibody testing}

Serum samples were taken between March 18 and April 30 for anti-SARS-CoV-2 IgG tests. Immunoglobulin G (IgG) antibodies against the S1 domain of the spike protein of SARS-CoV-2 were tested by the recent CE version (April 2020) of the commercial enzyme-linked immunosorbent assay from Euroimmun (Lübeck,
Germany) using the EUROIMMUN Analyzer I platform according to the manufacturer's protocol and as described previously [7]. Optical density was determined at $450 \mathrm{~nm}$ with reference wavelength at $630 \mathrm{~nm}$. A cut-off of $\geq 0.8$ (OD450nm) was considered as positive. Assays were performed in line with the guidelines of the German Medical Association (RiliBAK) with stipulated internal and external quality controls.

\section{Mice}

Female, C57Bl/6 N mice were maintained under specific pathogen-free conditions at the Präklinisches Experimentelles Tierzentrum (PETZ) Erlangen, Germany, and approved by the local ethics authorities of the Regierung of Unterfranken (\#55.2-2532.1-59/14). Nine-week-old mice were acclimated for 1 week, followed by a 3-week co-housing period before i.p. treatment with $2 \mathrm{mg} / \mathrm{kg}$ mouse methotrexate $(n=6)$ or vehicle (PBS; $n=6)$ started for three consecutive days before analysis. Two independent experiments were performed.

\section{Organoids}

Intestinal organoids were generated as previously described [8]. In short, the small intestine of wild-type C57Bl/6 J was removed, longitudinally opened, and villi were scraped out. Isolated intestinal crypts were resuspended in $25 \mu \mathrm{l} /$ well growth factor reduced Matrigel (Corning, NY, USA). Organoids were cultured in the incubator for at least 7 days before any experiments were performed. Medium was changed every 2 to 3 days and organoids were split once per week. Organoids were stimulated with $0.25,0.5$, or $1 \mathrm{mM}$ methotrexate for $6 \mathrm{~h}$ before analysis.

\section{Western blot}

Organoids were washed two times with PBS and then subsequently lysed with RIPA buffer. Protein extract were separated on a 4-12\% SDS-polyacrylamide gel, transferred to a nitrocellulose membrane, and stained with antibodies against murine ACE2 (R\&D systems). An antibody against murine $\beta$-actin (Abcam) was used as loading control. Densitometry analysis was performed using ImageJ.

\section{Histology}

Lung and intestinal tissue were fixed in $4 \%$ formalin. After deparaffinization, rehydration, and blocking, paraffin sections were stained using a primary antibody against murine ACE2 (R\&D systems). Slides have been developed using a DAB staining solution kit after incubation with a HRP-conjugated anti-goat secondary antibody. Quantification of stained area per slide was performed using ImageJ. 


\section{Statistical analysis}

Data are expressed as mean \pm s.d. Analysis was performed using Student's $t$ test, single comparison, or analysis of variance (ANOVA) test for multiple comparisons (two-way ANOVA followed by Tukey's or Bonferroni's multiple comparisons test). All experiments were conducted at least two times. $P$ values of 0.05 were considered significant and are shown as $p<0.05\left(^{*}\right), p<0.01$ $\left.{ }^{(* *)}\right)$, or $p<0.001{ }^{(* * *)}$. Graph generation and statistical analyses were performed using the Prism version 8 software (GraphPad, La Jolla, CA).

\section{Results}

\section{Initial case series}

We were first contacted by a group of four Caucasian women, aged between 53 and 62 years, who lived in different households in Germany and had traveled for ski holidays to Ischgl (Tyrol, Austria) from Feb 29 to March 4,2020 . They shared the car for going there (approximately 4-h ride) and stayed in the same room the entirety of their holiday. They regularly visited ski huts and restaurants for lunch and dinner. All of them were in good physical condition and none had concomitant diseases with the only exception that one of the four was on stable methotrexate treatment $(15 \mathrm{mg} /$ week $)$ for rheumatoid arthritis. Her arthritis was in remission.

All four remained healthy during the holidays, but 2 days after their return, three developed infectious symptoms including fever, cough, headache, and fatigue
(Fig. 1a). Anosmia was reported by all of them. The fourth woman taking methotrexate developed no symptoms. Five days after the start of symptoms, RNA tests for SARS-CoV-2 were taken from mucosal swabs and the three women with symptoms were all tested positive. The woman taking methotrexate showed a negative SARS-CoV-2 RNA test. Three weeks later, serums of all four women were tested for anti-SARS-CoV-2 IgG (Euroimmun ELISA). The three symptomatic women, who had previously tested positive for SARS-CoV-2 RNA, were also highly positive for anti- SARS-CoV-2 IgG, while the one on methotrexate remained negative. The three infected women recovered within 2 weeks without complications.

All women lived with their husbands in the respective households. No other family members lived in these households. Two of the three husbands of the infected women developed anosmia, fatigue, headache, and cough within 7 days after return of their wives. The third husband, living with one of the infected women, did not develop any symptoms. He was on stable treatment with methotrexate $(20 \mathrm{mg} /$ week) for psoriasis. Mucosal swab was done, in which that taken from one of the two infected husbands confirmed for COVID-19 RNA. Moreover, all four husbands (including the one of the healthy woman) were tested for anti-SARS-CoV-2 IgG. The two symptomatic husbands were highly positive for antiSARS-CoV-2 IgG, while the asymptomatic husband on methotrexate as well as the husband from the non-

a.

Initial Patient Group

Wife 1 $\square \square \square \square \square \square \square \square \square \Rightarrow$ Husband 1 $\square \square \square \square \square \square \square \square \square$ Wife $2 \square \square \square \square \square \square \square \square \square \Longrightarrow$ Husband $2 \square \square \square \square \square \square \square \square \square$ Wife $3 \square \square \square \square \square \square \square \square \square \Rightarrow$ Husband $3 \square \square \square \square \square \square \square \square \square$ Wife $4 \square \square \square \square \square \square \square \square \square \Rightarrow$ Husband $4 \square \square \square \square \square \square \square \square \square$

b. Confirmatory Cases

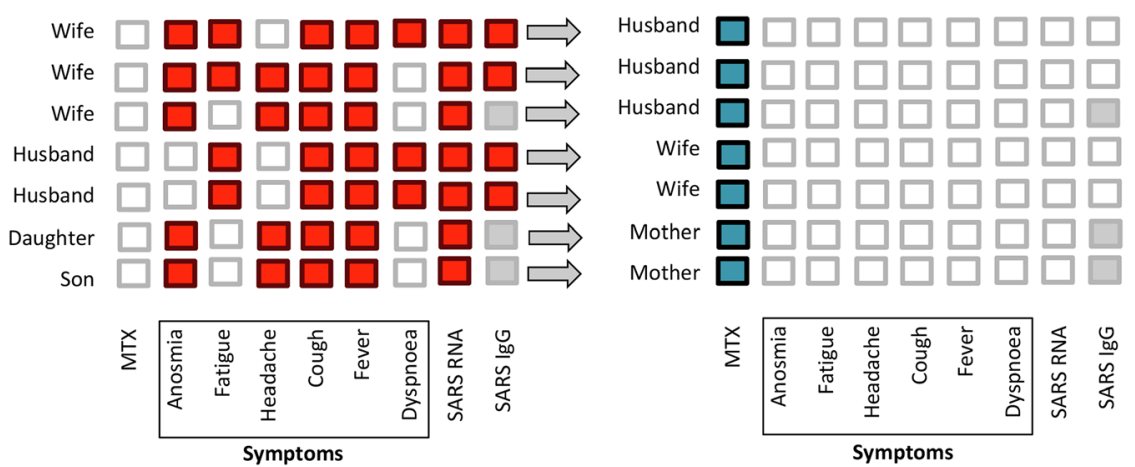

Fig. 1 MTX inhibits SARS-CoV-2 infection in highly exposed individuals. a Initial patient group of four women and their respective husbands. b Confirmatory cases. Symptoms related to COVID-19 and results of mucosal swabs for SARS-CoV-2 RNA and SARS-CoV-2 IgG antibody serum testing are shown. Red squares: positive or present; white squares: negative or absent; gray squares: not tested. Methotrexate use indicated by blue squares 
infected woman remained IgG negative. Both husbands with COVID-19 recovered from the infection without complications.

\section{Confirmatory cases}

Based on these observations we searched for additional families, in which one of the family members developed RNA- confirmed COVID-19, while the other family member taking MTX remained healthy. We identified 7 additional couples or parents/children, in whom the person taking methotrexate remained healthy and SARSCoV-2 RNA negative despite living in the same household and in close contact with a COVID-19 case. Four of the seven cases received MTX for rheumatoid arthritis, while the other three individuals had psoriatic arthritis or peripheral spondyloarthritis. Details of the disease symptoms are shown in Fig. $1 \mathrm{~b}$.

\section{Mechanistic studies}

As these observations suggested that MTX treatment is associated with at least some level of protection from COVID-19, we hypothesized that MTX may affect expression of ACE2, the receptor of the SARS-CoV-2 [1]. We therefore treated mice with MTX for 3 days and then tested the RNA expression of ACE2 in the lungs and in the intestine by RT-PCR. In addition, we tested ACE2 protein expression by immunohistochemistry in both organs. MTX treatment led to a significant downregulation of ACE2 mRNA (Fig. 2a) and protein expression (Fig. 2b and c) in the lungs and in the intestine. Furthermore, when intestinal organoids were treated with methotrexate at concentration reflecting human plasma levels in rheumatoid arthritis [9], ACE2 protein expression was down regulated (Fig. $2 \mathrm{~d}$ ).

\section{Discussion}

MTX is a widely and long-used drug to effectively treat IMIDs, in particular rheumatoid and psoriatic arthritis [10]. While doses of MTX used for the treatment of arthritis have potent ant-inflammatory properties, they are not generally immune suppressive and have not been shown to increase the risk of viral infections. MTX induces the generation of adenosine, which has antiinflammatory properties and likely mediated the
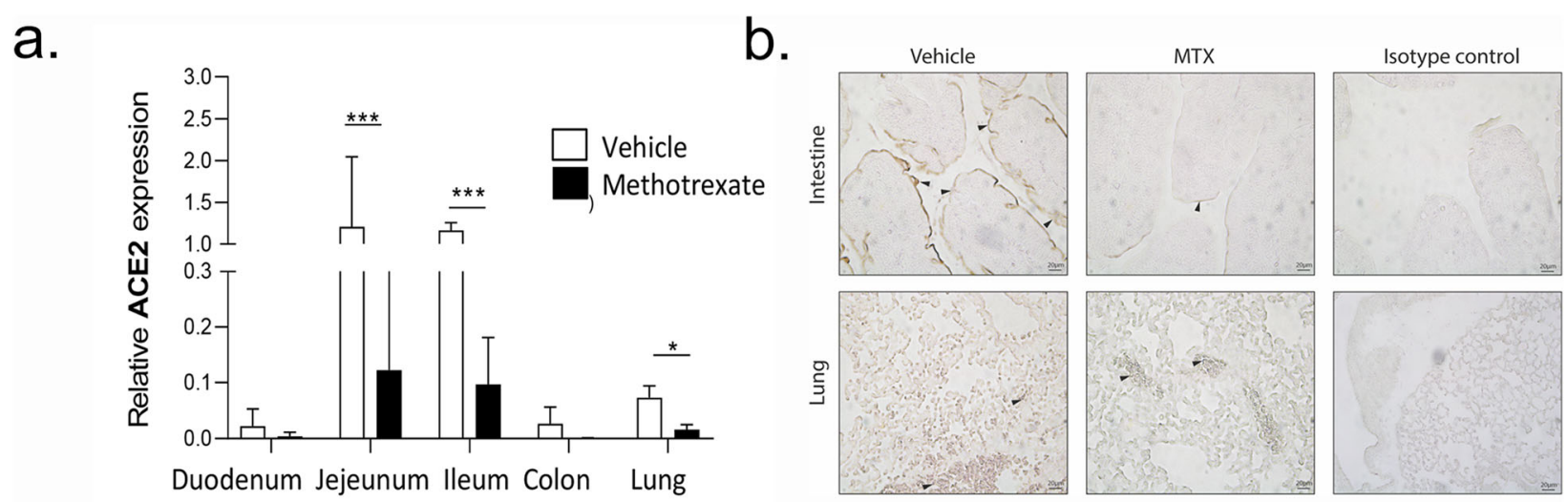

C.
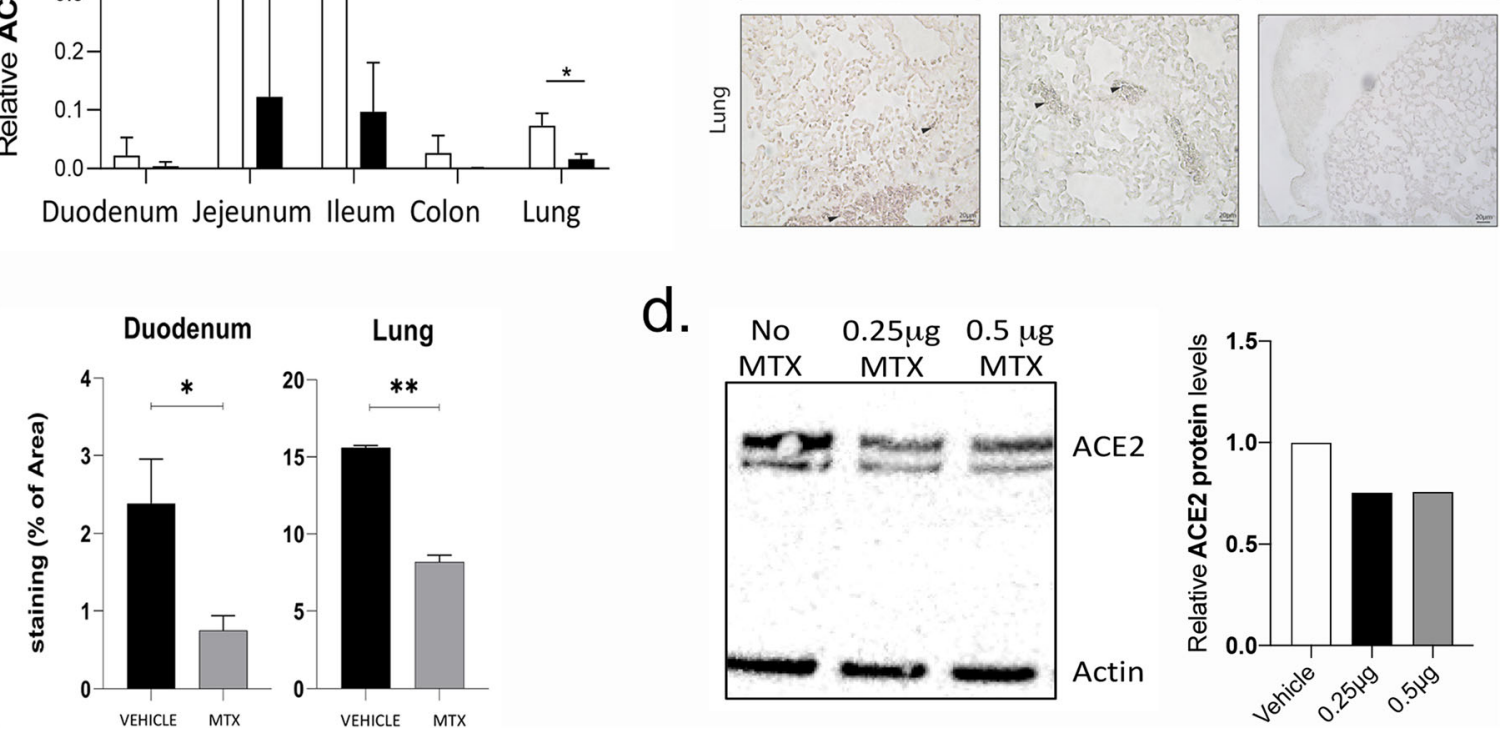

Fig. 2 MTX down-regulates ACE2 expression. a Real-time PCR showing quantification of mRNA for ACE2 in the various segments off the intestine and the lung in mice treated with methotrexate (MTX; $N=3$ per group per experiment; data summarized from two independent experiments). $\mathbf{b}$ Representative immune histochemistry staining for ACE2 (brown color, arrowheads) in the intestine and the lung of mice treated with methotrexate or vehicle for 3 days. Isotype control antibody staining is also shown. c Quantification of ACE2 expression in immune histochemistry ( $N=3$ per group per experiment; data summarized from two independent experiments). d Representative immunoblot for ACE2 and actin (control) in intestinal organoids treated with two doses of methotrexate including densitometric quantification 
inhibitory effect of MTX on arthritis [11, 12]. It is interesting that adenosine inhibits lung inflammation in the context of LPS challenge and also inhibits NETosis and thrombosis $[13,14]$, which are hallmarks of COVID-19 [15]. Previous data have also suggested a link between ACE2 expression and adenosine metabolism but have not described the regulation of ACE2 by MTX [16].

Our data show that MTX-treated patients can remain healthy despite long and close contact to SARS-CoV-2infected individuals, which is remarkable. Since MTX mitigates but not abrogates the expression of ACE2, the protective effect of MTX is definitely not complete and may be overridden by other factors such as high viral load or the aforementioned inducers of ACE2 expression. Cohorts investigating IMID patients with COVID19 have not shown a difference in the prevalence of MTX between mild (non-hospitalized) and severe (hospitalized) patients [17-19]. These observations suggest that MTX may not inhibit the hyper-inflammatory response in the patients infected by SARS-CoV-2. In contrast, our data support the role of MTX in viral entry through inhibition of ACE2 expression, which is different from the regulation of SARS-CoV-2-induced host response. The observation that the MTX-treated patients of the two case series remained RNA-negative underlines this concept.

A limitation of this study is that we cannot conclude from the case series and from the experimental data that methotrexate indeed lowers the risk for COVID-19. The study has not been designed to answer this question, which can only be addressed in larger prospective cohorts. Furthermore, murine data have certain limitations since mouse ACE2 bind less efficiently than human ACE2 to SARS viruses [20]. Nonetheless, the data open doors to study such concept and to consider that antiinflammatory drugs may not only influence the course of SARS-CoV-2 infection via modulation of inflammatory responses but also susceptibility to the infection via influencing virus entry. In addition, our data extend the concept that anti-inflammatory drugs used to treat diseases like rheumatoid arthritis are not broadly immune suppressive and may dampen rather than increase COVID-19 risk. In fact, several inflammatory pathways of the host that are induced by SARS-CoV-2 are shared by IMIDs such as arthritis [21]. In support, most studies so far showed that IMIDs treated with inhibitors of proinflammatory cytokines have no evidence for a more severe course of Covid-19 and with some treatments, e.g., TNF inhibitors, an even milder case of COVID-19 has been observed [16-18].

\section{Conclusion}

Taken together these clinical and functional data indicate that MTX may have a certain protective effect on
SARS-CoV-2 infection via downregulation of the expression of the viral receptor ACE2. However, to better define the inhibitory effect of methotrexate on the development of COVID-19, larger data sets including registry data and population-based data in high prevalence areas are needed.

\section{Abbreviations}

ACE2: Angiotensin-converting enzyme 2; COVID-19: Coronavirus disease 19; IMIDs: Immune-mediated chronic inflammatory diseases; MTX: Methotrexate; SARS-CoV-2: Severe acute respiratory syndrome coronavirus 2

\section{Acknowledgements}

Nothing to acknowledge.

\section{Authors' contributions}

$M M Z, F S$, and $K D$ did the experimental work. GB, RC, CF, and BM recruited the patients. GS wrote the manuscript. The authors read and approved the final manuscript.

\section{Funding}

This work was supported by the German Research Council (DFG) with projects CRC1181 (project INST 90/925-1; to GS), FOR 2886 (project SCHE 1583/15-1, to GS), and SCHE 1583/14-1 (to GS); the Bundesministerium für Bildung und Forschung (BMBF) with project Mascara (to GS); the IMI-funded project RTCure (115142) (to GS); the ERC grant 4D NanoScope from the European Union (to GS); and the Schreiber Stiftung (to GS).

\section{Availability of data and materials}

The datasets used and/or analyzed during the current study are available from the corresponding author on reasonable request.

\section{Declarations}

Ethics approval and consent to participate

All patients provided written informed consent and the institutional review board (IRB)/ethics committee (Ethik-Kommission der Friedrich-AlexanderUniversität Erlangen-Nürnberg) approved the study.

\section{Consent for publication}

Not applicable.

\section{Competing interests}

The authors declare no competing interests.

\section{Author details}

${ }^{1}$ Department of Internal Medicine 3, Friedrich-Alexander University (FAU) Erlangen-Nürnberg and Universitätsklinikum Erlangen, Erlangen, Germany. ${ }^{2}$ Deutsches Zentrum fuer Immuntherapie (DZI), Friedrich-Alexander University (FAU) Erlangen-Nürnberg and Universitätsklinikum Erlangen, Erlangen, Germany. ${ }^{3}$ Department of Rheumatology and Clinical Immunology, Charité, Berlin, Germany. ${ }^{4}$ Department of Clinical Sciences and Community Health, Research Center for Adult and Pediatric Rheumatic Diseases, University of Milan, G. Pini Hospital, Milan, Italy. ${ }^{5}$ Cobra Clinic of Rheumatology and Research Center, São Paulo, Brazil. ${ }^{6}$ Department of Rheumatology, University of Sao Paulo, São Paulo, Brazil.

Received: 7 October 2020 Accepted: 22 February 2021

Published online: 10 June 2021

\section{References}

1. Hoffmann M, Kleine-Weber H, Schroeder S, Krueger N, Herrler T, Erichsen S, et al. SARS-CoV-2 cell entry depends on ACE2 and TMPRSS2 and is blocked by a clinically proven protease inhibitor. Cell. 2020;181:271-80.

2. Huang C, Wang J, Li X, Ren L, Zhao J, Hu Y, et al. Clinical features of patients infected with 2019 novel coronavirus in Wuhan, China. Lancet. 2020;395: 497-506.

3. Chen K, Bi J, Su Y, Chappell MC, Rose JC. Sex-specific changes in renal angiotensin-converting enzyme and angiotensin-converting enzyme 2 gene 
expression and enzyme activity at birth and over the first year of life. Reprod Sci. 2016;23:200-10.

4. Bernardi S, Toffoli B, Zennaro C, Tikellis C, Monticone S, Losurdo P, et al. High-salt diet increases glomerular ACE/ACE2 ratio leading to oxidative stress and kidney damage. Nephrol Dial Transplant. 2012;27:1793-800.

5. Liu Y, Zhao L, Zhang Q, Zhang L, Ren G. Effect of long-term smoking on expression of serum ACE and ACE2 as well as its significance. J Taishan Med Coll. 2019:40:258-60.

6. Monteil V, Kwon H, Prado P, Hagelkrüys A, Wimmer RA, Stahl M, et al. Inhibition of SARS-CoV-2 infections in engineered human tissues using clinical-grade soluble human ACE2. Cell. 2020. https://doi.org/10.1016/j.cell.2 020.04.004.

7. Simon D, Tascilar K, Kroenke G, Kleyer A, Zaiss MM, Heppt F, et al. Patients with immune-mediated inflammatory diseases receiving cytokine inhibitors have low prevalence of SARS-CoV-2 seroconversion. Nat Commun. 2020;11: 3774.

8. Tajik N, Frech M, Schulz O, Schälter F, Lucas S, Azizov V, et al. Targeting zonulin and intestinal epithelial tight barrier function to prevent onset of arthritis. Nat Commun. 2020;11:1995.

9. Leeb B, et al. Methotrexate serum-level determinations during low-dose therapy of rheumatoid and psoriatic arthritis. Int J Clin Pharmacol Res. 1989; 9:209-15.

10. Weinblatt ME. Methotrexate: who would have predicted its importance in rheumatoid arthritis? Arthritis Res Ther. 2018;20:103.

11. Cronstein BN, Aune TM. Methotrexate and its mechanisms of action in inflammatory arthritis. Nat Rev Rheumatol. 2020;16:145-54.

12. Kremer J. Towards a better understanding of methotrexate. Arthritis Rheumatol. 2004;50:1370-82.

13. Friebe D, Yang T, Schmidt T, Borg N, Steckel B, Ding Z, Schrader J. Purinergic signaling on leukocytes infiltrating the LPS-injured lung. PLoS One. 2014;9:e95382.

14. Ali RA, Gandhi AA, Meng H, Yalavarthi S, Vreede AP, Estes SK, et al. Adenosine receptor agonism protects against NETosis and thrombosis in antiphospholipid syndrome. Nat Commun. 2019;10:1916.

15. Leppkes M, Knopf J, Naschberger E, Lindemann A, Singh J, Herrmann I, et al. Vascular occlusion y neutrophil extracellular taps in COVID-19. EBioMedicine. 2020:58:102925.

16. Patel VB, Zhong JC, Grant MB, Oudit GY. Role of the ACE2/angiotensin 1-7 Axis of the renin-angiotensin system in heart failure. Circ Res. 2016;118: $1313-26$.

17. Haberman R, Axelrad J, Chen A, Castillo R, Yan D, Izmirly P, et al. Covid-19 in immune-mediated inflammatory diseases - case series from New York. N Engl J Med. 2020;58:102925.

18. Haberman RH, Castillo R, Chen A, Yan D, Ramirez D, Sekar V, et al. COVID-19 in patients with inflammatory arthritis: a prospective study on the effects of comorbidities and DMARDs on clinical outcomes. Arthritis Rheumatol. 2020

19. Gianfrancesco M, Hyrich K, Al-Adely S, Carmona L, Danila Ml, Gossec L, et al. Characteristics associated with hospitalization for COVID-19 in people with rheumatic disease: data from the COVID-19 Global Rheumatology Alliance physician-reported registry. Ann Rheum Dis. 2020.

20. Li W, Greenough TC, Moore MJ, Vasilieva N, Somasundaran M, Sullivan JL, et al. Efficient replication of severe acute respiratory syndrome coronavirus in mouse cells is limited by murine angiotensin converting enzyme $2 . \mathrm{J}$ Virol. 2004;78:11429-33.

21. Schett G, Sticherling M, Neurath MF. COVID-19: risk for cytokine targeting in chronic inflammatory diseases? Nat Rev Immunol. 2020;20:271-2.

\section{Publisher's Note}

Springer Nature remains neutral with regard to jurisdictional claims in published maps and institutional affiliations.

Ready to submit your research? Choose BMC and benefit from:

- fast, convenient online submission

- thorough peer review by experienced researchers in your field

- rapid publication on acceptance

- support for research data, including large and complex data types

- gold Open Access which fosters wider collaboration and increased citations

- maximum visibility for your research: over $100 \mathrm{M}$ website views per year

At BMC, research is always in progress.

Learn more biomedcentral.com/submissions 